\title{
The ryanodine contracture test may help diagnose susceptiblity to malignant hyperthermia
}

\author{
[Le test de contracture à la ryanodine peut aider à découvrir une susceptibilité \\ à l'byperthermie maligne]
}

\author{
Daniel A. Reuter MD, * Martin Anetseder MD, $\uparrow$ Rainer Müller MD, $\dagger$ Norbert Roewer MD PhD,$\dagger$ \\ Edmund J. Hartung MD PhD
}

Purpose: The ryanodine contracture test (RCT) using the plant alkaloid ryanodine as the triggering agent has been proposed to reduce equivocal results of the in vitro caffeine-halothane-contracture test (IVCT), which is the accepted and standardized procedure to diagnose malignant hyperthermia $(\mathrm{MH})$. However, the response of skeletal muscle of non-MH affected patients (controls) to ryanodine has not yet been characterized.

Methods: Skeletal muscle biopsies were studied in 33 controls and in six patients with a history of fulminant $\mathrm{MH}$. Following the IVCT, the RCT was performed in all specimens using ryanodine I $\mu \mathrm{M}$. Onset time of contracture and time to reach a contracture level of $10 \mathrm{mN}$ above lowest resting tension and above predrug tension were calculated.

Results: With the standard IVCT, all controls were labelled $\mathrm{MH}$ non-susceptible; all clinically diagnosed $\mathrm{MH}$ patients were labelled $\mathrm{MH}$ susceptible. With ryanodine, control muscle differed from $\mathrm{MH}$ susceptible muscle regarding onset time of contracture (26 vs 3.8 $\min , P<0.05$ ) and time to reach a contracture of $10 \mathrm{mN}$ ( $49 \mathrm{vs}$ $12.5 \mathrm{~min}, P<0.05$; all median). Tissue viability and patient's age significantly influenced contracture times.

Conclusions: Despite the highly specific binding of ryanodine at the myocytic sarcoplasmic reticulum, the wide range of contracture times of the controls points toward heterogeneity of ryanodine receptors within physiologic limits. This may also be caused in part by tissue viability and the patients' age. The ryanodine contracture test performed in addition to the IVCT may add clarity into diagnosing a patient as $\mathrm{MH}$-susceptible or not.
Objectif : Le test de contracture à la ryanodine (TCR), qui utilise un alcaloïde de la ryania comme agent déclencheur, a été proposé pour réduire les résultats équivoques du test de contracture in vitro à la caféine-halothane (TIVC), lequel est accepté et normalisé pour le diagnostic de l'hyperthermie maligne (HM). Cependant, la réaction des muscles squelettiques des patients non affectés d'HM (témoins) à la ryanodine n'a pas encore été définie.

Méthode : Des biopsies de muscles squelettiques ont été étudiées chez 33 témoins et six patients présentant des antécédents d'HM fulminante. À la suite du TIVC, le TCR a été réalisé pour tous les prélèvements en utilisant I $\mu \mathrm{M}$ de ryanodine. Ont été calculés : le délai d'installation de la contracture et le temps nécessaire pour atteindre un niveau de $10 \mathrm{mN}$ au-dessus de la plus faible tension de repos et au-dessus de la tension de prémédication.

Résultats : Pour le TIVC standard, les témoins ont été étiquetés comme non susceptibles d'HM et les patients ayant un diagnostic d'HM, comme susceptibles d'HM. Pour le test à la ryanodine, les muscles témoins différaient des muscles susceptibles d'HM, quant au délai d'installation de la contracture (26 vs 3,8 min, $P<0,05)$ et au temps nécessaire pour obtenir une contracture de $10 \mathrm{mN}$ ( 49 vs 12,5 min, $P<0,05$; médiane). La viabilité tissulaire et l'âge des patients ont eu une influence significative sur les temps de contracture.

Conclusion : Malgré une importante fixation de la ryanodine au réticulum sarcoplasmique myocytaire, la grande variation des temps de contracture des témoins indique une hétérogénéité des récepteurs de ryanodine qui se situe à l'intérieur des limites physiologiques. Cette situation peut dépendre aussi, en partie, de la viabilité tissulaire et de l'âge du patient. Le test de contracture à la ryanodine, ajouté au TIVC, peut aider à poser le diagnostic de susceptibilité ou non à l'HM.

From the Departments of Anesthesiology, University of Munich; ${ }^{*}$ and the University of Würzburg; $†$ and the Department of Anesthesiology and Intensive Care Medicine, Stralsund Academic Teaching Hospital, University of Greifswald, ‡ Stralsund, Germany. Address corresspondence to: Dr. Daniel A. Reuter, Department of Anesthesiology, University of Munich, Marchioninistr.15, D-81377

Munich, Germany. Phone +49-89-7097-1844; Fax +49-89-7097-1848; E-mail: Daniel.Reuter@ana.med.uni-muenchen.de

No financial support was received to perform this study. Accepted for publication February 19, 2003.

Revision accepted May 2, 2003. 
$M$ ALIGNANT hyperthermia $(\mathrm{MH})$ is a life-threatening syndrome triggered by volatile anesthetics and depolarizing muscle relaxants. The standard test for diagnosing the susceptibility for $\mathrm{MH}$ (MHS) is the in vitro contracture test with halothane and caffeine (IVCT). The settings and the performance of this test have been standardized and validated internationally in multicentre studies. ${ }^{1-3}$

Ryanodine, a plant alkaloid, causes time- and doserelated contractures of human skeletal muscle. It binds with high affinity to the ryanodine receptor protein (RYRl), a calcium channel at the sarcoplasmic reticulum. $^{4,5}$ While micro molar concentrations induce a prolonged opening of the calcium channel, higher concentrations close this channel. Several different mutations in the gene encoding the ryanodine receptor on chromosome 19q13.1 were described in 20 to $40 \%$ of families with a disposition to $\mathrm{MH}$. These mutations were found to alter the structure of the ryanodine receptor suggesting the RYRl as the probable site of the $\mathrm{MH}$ causing defect. ${ }^{6-9}$ Ryanodine induces contractures in MHS earlier than in non-susceptible (MHN) muscle. Hence, an in vitro contracture test using ryanodine as the pharmacological trigger (RCT) has been proposed to supplement the IVCT and thereby improve specificity and reduce equivocal results. ${ }^{10-12}$ In an earlier study by our laboratory, primary results of the RCT in 24 healthy individuals have been compared to the range of contractures induced in skeletal muscle of five patients having survived a fulminant $\mathrm{MH}$ episode and the general usefulness of this test was demonstrated. ${ }^{13}$ However, potential patient- or testing procedurerelated influences on the RCT have so far not been investigated, which is a prerequisite for the implementation of a new diagnostic test.

\section{Methods}

In vitro contracture testing for MHS was performed in 39 patients using the IVCT and the RCT.

\section{Control group}

With approval of the Institutional Review Board and with informed consent, a muscle biopsy of the vastus lateralis muscle was performed in 33 patients undergoing elective hip surgery. Patients with any personal or family history or evidence of a neuromuscular disease, patients who could not walk at least $100 \mathrm{~m}$ unaided, patients with elevated creatine kinase levels or those receiving calcium channel blocking agents were excluded. After premedication with midazolam $7.5 \mathrm{mg}$ po before surgery, all patients received lumbar intrathecal anesthesia at L3-4 using 24 G Sprotte intraspinal needles and hyperbaric mepivacaine 120 to $160 \mathrm{mg}$. Following skin incision and exposure of the fascia, a $2.5 \times 2 \times 0.5 \mathrm{~cm}$ biopsy of the vastus lateralis muscle was obtained for in vitro $\mathrm{MH}$ testing.

\section{MHS patients}

Diagnostic in vitro contracture testing was performed in six patients, who were referred to our laboratory because of a clinical episode of $\mathrm{MH}$ in their medical history. $\mathrm{MH}$ clinical grading scale in these patients showed a score of $>50$ making a diagnosis of $\mathrm{MH}$ highly reliable. ${ }^{14} \mathrm{~A}$ biopsy of the vastus lateralis muscle of $2.5 \times 2 \times 0.5 \mathrm{~cm}$ was performed under regional anesthesia with a femoral nerve block using mepivacaine $7 \mathrm{mg} \cdot \mathrm{kg}^{-1}$ body weight. The biopsy specimens were treated as described below.

\section{In vitro contracture testing}

After removal of connective tissue, muscle biopsies were divided into single muscle bundles measuring 15 to $20 \mathrm{~mm}$ in length and 2 to $3 \mathrm{~mm}$ in diameter. Four muscle bundles per patient were tested with the IVCT according to the European protocol and diagnosis of MHS or MHN was established. ${ }^{2,3}$

\section{Ryanodine contracture test}

The RCT was performed on fresh muscle bundles. Length and wet weight of each bundle was determined. Then, muscle bundles were fixed with one end statically in the testing chamber, which was continuously perfused with Krebs-Ringer solution (4 $\mathrm{mL} \cdot \mathrm{min}^{-1}, 37^{\circ} \mathrm{C}$ ) and carboxygenated with $95 \%$ $\mathrm{O}_{2} / 5 \% \mathrm{CO}_{2}$. The other end of the muscle bundle was tied to an isometric force transducer (Lectromed Type 4150, Letchworth, UK). The specimens were then mounted vertically and stimulated with a supramaximal electrical square wave stimulus at $0.2 \mathrm{sec}^{-1}$ and 1 msec duration (Hugo-Sachs-Elektronik, Type 215/I, March-Hugstetten, Germany). The force transducer signal was amplified and recorded continuously on a plotter (Rikadenki Model R-64, Freiburg, Germany) reflecting resting tension and twitch amplitude.

Each muscle bundle was preloaded for a maximum twitch response and equilibrated until resting tension did not decrease more than $2 \mathrm{mN}$ within ten minutes. Muscle bundles with a twitch amplitude of less than $10 \mathrm{mN}$ were excluded. After equilibration the pumpcontrolled perfusion with Krebs-Ringer-solution was stopped and high-purity ryanodine (Calbiochem, La Jolla, CA, USA, stock solution $100 \mu \mathrm{M})$ was added (predrug, $\mathrm{t}=0 \mathrm{~min}$ ), achieving a concentration of $\mathrm{l}$ $\mu \mathrm{M}$ in the testing chamber. Maximum resting tension 
TABLE I Biometric data of muscle bundles used for the ryanodine contracture test (RCT)

\begin{tabular}{llll}
\hline & \multicolumn{2}{l}{ Control group } & $\begin{array}{l}\text { Fulminant } \\
\text { MH }\end{array}$ \\
& Test 1 & Test 2 & $\begin{array}{l}\text { RCT } \\
n=6\end{array}$ \\
& $n=33$ & $n=15$ & $n=6.5$ \\
\hline Length $(\mathrm{mm})$ & $15.8 \pm 0.2$ & $16.2 \pm 0.5$ & $17.6 \pm 2.1$ \\
Weight $(\mathrm{mg})$ & $233 \pm 49$ & $222 \pm 8$ & $188 \pm 49$ \\
Maximum tension $(\mathrm{mN})$ & $31.9 \pm 8.6$ & $27.5 \pm 7.1$ & $23.5 \pm 2.5^{*}$ \\
Predrug tension $(\mathrm{mN})$ & $10.8 \pm 6.5$ & $11.3 \pm 3.9$ & $10.8 \pm 3.7$ \\
Predrug twitch $(\mathrm{mN})$ & $31.9 \pm 18.6$ & $27.5 \pm 7.1$ & $50.3 \pm 19.4^{*}$ \\
\hline
\end{tabular}

*Significantly different from control group $(P<0.05)$. MH $=$ malignant hyperthermia.

after preloading (Max), resting tension before application of ryanodine (Predrug), minimum resting tension after equilibration (Min) and twitch amplitude before administration of ryanodine (Predrug twitch) were recorded. The course of the resting tension after application of ryanodine was evaluated according to two different methods that were proposed (Figure): regarding method 1 , graphically determined measurement points were: time from addition of ryanodine to onset of contracture (OT) and time to reach a contracture of $10 \mathrm{mN}$ above minimum resting tension $(10 \mathrm{~T})$ as well as the interval between OT and $10 \mathrm{~T}$ $(\Delta \mathrm{T}=10 \mathrm{~T}-\mathrm{OT})$; regarding method 2: time from addition of ryanodine to onset of contracture above predrug resting tension (OTp), time to reach a contracture of $10 \mathrm{mN}$ above predrug resting tension $(10 \mathrm{Tp})$ and the interval between OTp and 10Tp $(\Delta \mathrm{Tp}$ $=10 \mathrm{Tp}-\mathrm{OTp}$ ). Each test was terminated when 10Tp was reached or testing time had exceeded $99 \mathrm{~min}$. In muscle bundles that did not achieve a contracture of $10 \mathrm{mN}$ within $99 \mathrm{~min}, 10 \mathrm{~T}$ and $10 \mathrm{Tp}$ were set 100 min for statistical purposes. A second RCT was performed, if further and viable (twitch amplitude $>10$ $\mathrm{mN}$ ) muscle bundles were available.

\section{Statistics}

Results are presented as medians and ranges. The test of Kolmogorov-Smirnov with Lilliefort's correction was used to test data for normality of the estimated underlying population. The parametric paired test was used to identify differences. The parametric Pearson's product-moment relation and the non-parametric Spearman's rank correlation were used to measure the strength of association between pairs of variables. $P<0.05$ was considered to be statistically significant.

\section{Results}

\section{Control group}

Thirty-three patients, 20 female and 13 male, with a mean age of $55 \pm 13.2 \mathrm{yr}$ were studied. Diagnosis of MHN was confirmed by the IVCT according to the criteria of the European protocol. The RCT was performed in all patients. In 15 patients a second RCT could be performed due to a sufficient amount of muscle tissue. Muscle bundles used for the RCT and IVCT did not differ regarding length, weight and preload resting tension (Table I).

Ryanodine-induced contractures evolved at a median of $26 \mathrm{~min}(\mathrm{OT})$ with a shallow slope and reached a contracture of $10 \mathrm{mN}$ at a median of $48.9 \mathrm{~min}(10 \mathrm{~T})$ and a $\Delta \mathrm{T}$ of $20.8 \mathrm{~min}$ (Table II). Test results of the first and second RCT did not differ significantly. Viability of the muscle bundles, quantified by predrug twitch amplitude influenced OT $\left(\mathrm{r}^{2}=0.45 ; P<0.05\right)$ and OTp $\left(\mathrm{r}^{2}=0.44 ; P<0.05\right)$ as well as $10 \mathrm{~T}\left(\mathrm{r}^{2}=0.67 ; P<\right.$ $0.001)$ and $10 \mathrm{Tp}\left(\mathrm{r}^{2}=0.59 ; P<0.001\right)$ significantly. There was no correlation between age or gender and predrug twitch amplitude. The patients' age showed a significant correlation to onset times OT $\left(\mathrm{r}^{2}=0.49 ; P\right.$ $<0.001)$ and $\mathrm{OTp}\left(\mathrm{r}^{2}=0.49 ; P<0.001\right)$ as well as contracture times 10T $\left(\mathrm{r}^{2}=0.57 ; P<0.001\right)$ and $10 \mathrm{Tp}\left(\mathrm{r}^{2}\right.$ $=0.51 ; P<0.001)$.

\section{MHS patients}

Six patients, two female and four male, who had survived fulminant $\mathrm{MH}$ episodes were investigated by the IVCT and RCT as described above. Mean age was 31

TABLE II Ryanodine contracture test (RCT) in control patients $(n=33)$ and in MHS patients $(n=6)$

\begin{tabular}{|c|c|c|c|c|c|}
\hline & & Control & group & Fulmina & $n t M H$ \\
\hline & & Median & Range & Median & Range \\
\hline $\mathrm{OT}[\mathrm{min}]$ & Test 1 & 26 & $12.5-70.8$ & $3.8^{*}$ & $0.5-8.3$ \\
\hline & Test 2 & 27.5 & $12.2-63.8$ & & \\
\hline $10 \mathrm{~T}[\mathrm{~min}]$ & Test 1 & 48.9 & $25.8-100$ & $12.5^{*}$ & $4.0-15.6$ \\
\hline & Test 2 & 48.0 & $26.6-100$ & & \\
\hline$\Delta \mathrm{T}[\min ]$ & Test 1 & 20.8 & $10.8-68.7$ & $6.1^{*}$ & $3.5-11.0$ \\
\hline & Test 2 & 19.5 & $10.5-55.0$ & & \\
\hline $\mathrm{OTp}[\min ]$ & Test 1 & 30.0 & $15.8-85.0$ & $3.8^{*}$ & $1.3-8.3$ \\
\hline & Test 2 & 31.0 & $13.0-88.0$ & & \\
\hline 10Tp [min] & Test 1 & 50.4 & $26.0-100$ & $12.7^{*}$ & $4.4-16.1$ \\
\hline & Test 2 & 48.0 & $26.7-100$ & & \\
\hline$\Delta \mathrm{Tp}[\mathrm{min}]$ & Test 1 & 15.0 & $2.3-49.5$ & $5.7^{*}$ & $3.1-11.0$ \\
\hline & Test 2 & 13.5 & $6.5-54.0$ & & \\
\hline
\end{tabular}

* Significantly different from control group $(P<0.05)$. Fifteen out of 33 contracture tests in the control group were performed twice in the same individual. OT $=$ onset time of contracture after administration of ryanodine; OTp = time when contracture reached predrug level; $10 \mathrm{~T}=$ time to reach a contracture of 10 $\mathrm{mN}$ above OT level; $10 \mathrm{Tp}=$ time when contracture reached 10 $\mathrm{mN}$ above predrug level. $\mathrm{MH}=$ malignant hyperthermia . 


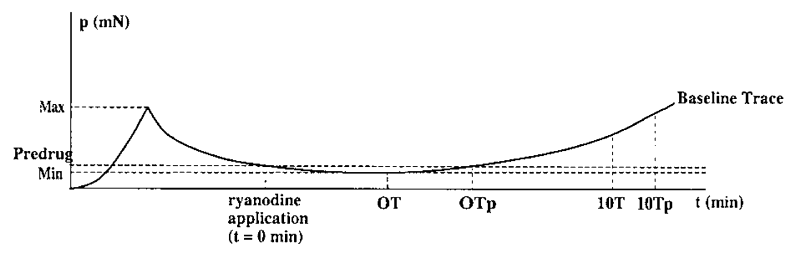

FIGURE Data evaluation during the ryanodine contracture test The schematic baseline trace of a ryanodine contracture test illustrates the variables measured. Max $=$ maximum baseline tension after preloading; Predrug $=$ baseline tension before drug administration; $\mathrm{Min}=$ minimum baseline tension; $\mathrm{OT}=$ onset time of contracture after administration of ryanodine; OTp = time when contracture reached predrug level; $10 \mathrm{~T}=$ time to reach a contracture of $10 \mathrm{mN}$ above OT level; $10 \mathrm{Tp}=$ time when contracture reached $10 \mathrm{mN}$ above predrug level.

$\mathrm{yr}$, ranging from six to $54 \mathrm{yr}$. All patients were tested MHS by the IVCT. With ryanodine, contractures developed early with a median in onset time $(\mathrm{OT})$ of $3.8 \mathrm{~min}$ and $12.5 \mathrm{~min}$ in $10 \mathrm{mN}$ contracture time (10T; Table II). No correlation between predrug twitch amplitude and contracture times OT, OTp $10 \mathrm{~T}, 10 \mathrm{Tp}, \Delta \mathrm{T}$ or $\Delta \mathrm{Tp}$ or patients' age were found.

There was no overlap of individual contracture data for the onset times OT and OTp as well as for the contracture times $10 \mathrm{~T}$ and $10 \mathrm{Tp}$ between healthy controls and $\mathrm{MH}$ patients, while the range of $\Delta \mathrm{T}$ overlapped slightly.

\section{Discussion}

The Gold standard for the diagnosis of MHS is the IVCT with caffeine and halothane. The standardized investigational protocol for the IVCT in Europe, the European protocol, is internationally accepted and diagnostic criteria (i.e., thresholds) are established and validated. ${ }^{2,3}$ However, the $\mathrm{MH}$ diagnostic procedure according to the European protocol produces a group of 10 to $15 \%$ of patients who cannot conclusively be diagnosed as either MHS or MHN. ${ }^{3}$

Ryanodine binds equimolarly to the sarcoplasmic calcium release channel, the so called ryanodine receptor, and was therefore considered to be a more specific triggering agent than halothane or caffeine. ${ }^{10}$ Both of the latter two agents have other sites of action, e.g., inhibition of the sarcoplasmic Ca-ATPase and phosphodiesterase, respectively. ${ }^{15}$ Ryanodine, devoid of these secondary effects, was proposed as a favourable substance to diagnose MHS by a contracture test and thus to reduce equivocal results (MHE) of the IVCT. ${ }^{10-12,16}$ Published data comparing results of MHS, MHE and MHN patients support this contention. ${ }^{13}$ Since the definition, validation and reproducibility of diagnostic thresholds as well as the identification of patient and testing procedure associated influences is of paramount importance for a diagnostic test, we investigated skeletal muscle of patients with no personal or family history of any neuromuscular disease or anesthesia complication. The diagnosis of MHN was confirmed in all control patients. The prevalence of MHS in a normal population is estimated to be $1: 10,000$ to $1: 20,000$. Therefore it is highly unlikely that a patient susceptible to $\mathrm{MH}$ was not detected by the described method and thus influenced the results presented. Consequently, the contracture data shown in Table II represent the response of healthy human muscle exposed to ryanodine $1.0 \mu \mathrm{M}$ in this testing procedure to which values of MHS patients can be compared.

We investigated six patients by the RCT, who had survived a fulminant episode of $\mathrm{MH}$. The inclusion was based on their individual score on the $\mathrm{MH}$ clinical grading scale. This scale is the only instrument available at present to confirm a true $\mathrm{MH}$ episode with a high likelihood. ${ }^{14}$ Contracture data of skeletal muscle derived from these $\mathrm{MH}$ patients did not overlap with controls regarding the contracture times OT, OTp, 10T and 10Tp (Table II).

Regarding the validation process of the ryanodine contracture test, MHN patients, who are referred for $\mathrm{MH}$-testing because of clinical symptoms of $\mathrm{MH}$, have a genetic linkage to MHS patients, or present with other neuromuscular abnormalities and cannot serve as controls. The MH unrelated patients investigated here did not meet any of those exclusion criteria. Therefore these data allow the definition of normal values for the RCT, at least for our laboratory. However, the contracture data regarding the variables OT, 10T, OTp and 10Tp are comparable with published data from MHN patients. ${ }^{11,12}$

We investigated the possible influence of methodological factors such as pre-testing viability of the muscle bundles, patients' sex and age on the RCT. Viability of the tested muscle bundles was ensured by applying the viability criterion of the European protocol, i.e., a minimum predrug twitch amplitude of 10 $\mathrm{mN}$. Still, this variable significantly influenced the onset times OT and OTp, as well as the contracture times $10 \mathrm{~T}$ and $10 \mathrm{Tp}$. While these contracture times showed good reproducibility by repeated testing, the contracture times $\Delta \mathrm{T}$ and $\Delta \mathrm{Tp}$ did not. Additionally, the ranges of the latter two variables were quite large, 
overlapped between groups and are therefore of little value for diagnostic purposes.

We found a statistically significant inverse correlation between age and all contracture times, i.e., muscle bundles of older patients showed shorter onset times OT and OTp as well as contracture times 10T and $10 \mathrm{Tp}$, suggesting that, at least for the ryanodine contracture test, different diagnostic thresholds for different age groups should be considered. A possible influence of age was reported in young pigs at the age of five weeks, where contracture response to halothane/succinylcholine in vivo was delayed, whereas contracture response under halothane in vitro was absent. ${ }^{17}$ Four cases of children aged six to 11 presenting clinical signs strongly suggestive of an $\mathrm{MH}$ episode, but with negative contracture tests according to the North American Malignant Hyperthermia Registry standards, were reported. ${ }^{18}$ This may point toward a neglected influence of age on the results of the IVCT. Since the age range in our control group limits interpretation, the correlation between contracture and age remains to be elucidated.

$\mathrm{MH}$ laboratories have reported overlaps between the results for contracture between the IVCT and the RCT regarding the diagnosis of MHN and MHS. ${ }^{19}$ There are several possible reasons for these overlapping results between laboratories: first, results of the IVCT with halothane and caffeine might have been incorrect due to methodological differences. This is fairly unlikely because of the international agreement regarding performance and interpretation of the IVCT. Second, values of the RCT were different due to differences in performance of the test. In the first multicentre analysis of ryanodine contracture testing results including 11 European centres, the authors described significant variability in ryanodine responses between several centres, obviously due to different techniques. ${ }^{19}$ Therefore, this new test requires standardization of the methodology and performance comparable to that of the IVCT. This inter-centre variability in ryanodine response, however, might also be influenced by different $\mathrm{MH}$-associated ryanodine receptor gene mutations. ${ }^{20,21}$

In conclusion, the contracture times with ryanodine $1.0 \mu \mathrm{M}$ in MHS and in MHN muscle are different and do not overlap. However, the wide range of contracture times within the control group points toward a possible variety of functionally different ryanodine receptors. A good intraindividual reproducibility confirms the reliability of the test within our laboratory, whereas a multicentre study revealed a high inter-centre variability. Standardization of methodology and diagnostic criteria may help to over- come this problem. Performing the ryanodine contracture test in addition to the halothane/caffeine contracture test may add more clarity into diagnosing a patient as MHS or not.

\section{References}

1 Allen GC, Larach MG, Kunselman AR. The sensitivity and specificity of the caffeine-halothane contracture test. A report from the North American Malignant Hyperthermia Registry. The North American Malignant Hyperthermia Registry of MHAUS. Anesthesiology 1998; 88: 579-88.

2 The European Malignant Hyperpyrexia Group. A protocol for the investigation of malignant hyperpyrexia (MH) susceptibility. Br J Anaesth 1984; 56: 1267-9.

3 Ording $H$, Brancadoro V, Cozzolino $S$, et al. In vitro contracture test for diagnosis of malignant hyperthermia following the protocol of the European $\mathrm{MH}$ group: Results of testing patients surviving fulminant $\mathrm{MH}$ and unrelated low-risk subjects. The European Malignant Hyperthermia Group. Acta Anaesthesiol Scand 1997; 41: 955-66.

4 Lai FA, Erickson HP, Rousseau E, Lui QY, Meissner G. Purification and reconstitution of the calcium release channel from skeletal muscle. Nature 1988; 331: 315-9.

5 MacLennan DH, Phillips MS. Malignant hyperthermia. Science 1992; 256: 789-94.

6 MacLennan DH, Duff C, Zorzato F, et al. Ryanodine receptor gene is a candidate for predisposition to malignant hyperthermia. Nature 1990: 343: 559-61.

7 McCarthy TV, Healy JM, Heffron JJ, et al. Localization of the malignant hyperthermia susceptibility locus to human chromosome 19q12-13.2. Nature 1990; 343: 562-4.

8 Mickelson JR, Gallant EM, Litterer LA, Johnson KM, Rempel WE, Louis CF. Abnormal sarcoplasmic reticulum ryanodine receptor in malignant hyperthermia. J Biol Chem 1988; 263: 9310-5.

9 Fujii J, Otsu K, Zorzato F, et al. Identification of a mutation in porcine ryanodine receptor associated with malignant hyperthermia. Science 1991; 253: 448-51.

10 Hopkins PM, Ellis FR, Halsall PJ. Ryanodine contracture: a potentially specific in vitro diagnostic test for malignant hyperthermia. Br J Anaesth 1991; 66: 611-3.

11 Lenzen C, Roewer N, Wappler F, et al. Accelerated contractures after administration of ryanodine to skeletal muscle of malignant hyperthermia susceptible patients. Br J Anaesth 1993; 71: 242-6.

12 Wappler F, Roewer N, Köchling A, Scholz J, Steinfath M, Schulte am Esch J. In vitro diagnosis of malignant hyperthermia susceptibility with ryanodine-induced 
contractures in human skeletal muscles. Anesth Analg 1996; 82: 1230-6.

13 Hartung E, Koob M, Anetseder M, et al. Malignant hyperthermia $(\mathrm{MH})$ diagnostics: a comparison between the halothane-caffeine- and the ryanodine-contracturetest results in $\mathrm{MH}$ susceptible, normal and control muscle. Acta Anaesthesiol Scand 1996; 40: 437-44.

14 Larach $M G$, Localio AR, Allen GC, et al. A clinical grading scale to predict malignant hyperthermia susceptibility. Anesthesiology 1994; 80: 771-9.

15 Blanck TJ, Gruener R, Suffecool SL, Thompson M. Calcium uptake by isolated sarcoplasmic reticulum: examination of halothane inhibition, $\mathrm{pH}$ dependence, and $\mathrm{Ca}^{2+}$ dependence of normal and malignant hyperthermic human muscle. Anesth Analg 1981; 60: 492-8

16 Hopkins PM, Ellis FR, Halsall PJ. Comparison of in vitro contracture testing with ryanodine, halothane and caffeine in malignant hyperthermia and other neuromuscular disorders. Br J Anaesth 1993; 70: 397-401.

17 Fay RS, Gallant EM. Halothane sensitivity of young pigs in vivo and in vitro. Am J Physiol 1990; 259: R133-8.

18 Wedel DJ, Nelson TE. Malignant hyperthermia-diagnostic dilemma: false-negative contracture responses with halothane and caffeine alone. Anesth Analg 1994; 78: 787-92.

19 Hopkins PM, Hartung E, Wappler F. Multicentre evaluation of ryanodine contracture testing in malignant hyperthermia. The European Malignant Hyperthermia Group. Br J Anaesth 1998; 80: 389-94.

20 Fiege M, Wappler F, Weisshorn R, Gerbershagen MA, Steinfath $M$, Schulte am Esch J. Results of contracture tests with halothane, caffeine, and ryanodine depend on different malignant hyperthermia-associated ryanodine receptor gene mutations. Anesthesiology 2002; 97: 345-50.

21 Robinson RL, Brooks C, Brown SL, et al. RYRl mutations causing central core disease are associated with more severe malignant hyperthermia in vitro contracture test phenotypes. Hum Mutat 2002; 20: 88-97. 